\title{
Bacterial Vaginosis and Correlates in Women of Reproductive Age in Thika, Kenya
}

\author{
J. Nzomo ${ }^{1}$, P. Waiyaki ${ }^{2}$, R. Waihenya ${ }^{3}$ \\ ${ }^{1}$ Ministry of Medical Services, Machakos, Kenya \\ ${ }^{2}$ Centre for Microbiology Research and KEMRI, Nairobi, Kenya \\ ${ }^{3}$ Jomo Kenyatta University of Agriculture and Technology, Juja, Kenya \\ Email: pgwaiyaki@gmail.com, wanjikukinge@gmail.com
}

Received March 8, 2013; revised April 9, 2013; accepted May 9, 2013

Copyright (C 2013 J. Nzomo et al. This is an open access article distributed under the Creative Commons Attribution License, which permits unrestricted use, distribution, and reproduction in any medium, provided the original work is properly cited.

\begin{abstract}
Background: Bacterial vaginosis (BV) is the most common cause of abnormal vaginal discharge among women of childbearing age which is associated with STI/HIV and adverse birth outcomes. The Main objective of this study was to determine the prevalence and correlates of BV among women of reproductive age in Thika. Methods: Between July 2010 and February 2011, 193 women of reproductive age (18 - 49 years) were enrolled from family planning and ante-natal clinics in Thika District Hospital, Kenya. The study was descriptive cross sectional in which organisms were identified from vaginal specimens using culture, biochemical testing and Nugent score method. Statistical analyses included conventional descriptive statistics and multivariable analysis using regression. Results: Of one hundred and ninety three specimens, 9.3\% were Mobiluncus isolates, 23.0\% Bacteriodes species and 67.7\% Gardnerella vaginalis. Among the study participants, $77.7 \%$ had non-classical BV with a score of 7 - 8 while $22.3 \%$ classical BV with a score of 9 - 10 indicating complete depletion of Lactobacillus species. Whiff test was positive for $89.1 \%$ (74) of the 83 patients with BV. Though, $32.5 \%$ of women with BV had a vaginal $\mathrm{pH}$ of more than 4.5, only $66.0 \%$ of women fulfilling the criteria of BV had a characteristic discharge. Conclusions: In this population, the prevalence of BV was relatively high when compared with other community settings. BV was associated with condom use and multiple sexual partners. Further research is needed to understand their role in BV and the socioeconomic context surrounding the condition in Kenya.
\end{abstract}

Keywords: Bacterial Vaginosis; Epidemiology; Prevalence

\section{Introduction}

The global burden of sexually transmitted diseases continues to grow and tackling them constitutes a major challenge for development into the modern society. The rapidly increasing burden of these diseases affects the poor and disadvantaged populations disproportionately, contributing to widening health gaps between and within populations. It's estimated that more than 36 million adults are infected with sexually transmitted infections (STIs), especially gonorrhoea, syphilis, trichomoniasis, chlamydia and genital herpes [1,2]. Bacterial vaginosis (BV) is the most common cause of abnormal vaginal discharge among women of childbearing age and is associated with low birth weight infants and preventable preterm births $[3,4]$. Some studies have found a relationship between BV and high-risk behaviors associated with sexually transmitted infections (STIs) such as early sex- ual debut and multiple sex partners [5,6].

$\mathrm{BV}$ is of special public health concern in Kenya because of the high burden of reproductive and pregnancyrelated morbidity [6,7]. In this study, Nugent score and culture methods were used to investigate prevalence of $\mathrm{BV}$ and its correlates in women of reproductive age in Thika, Kenya.

\section{Materials and Methods}

\section{Study Population}

This was descriptive cross sectional study which involved women of reproductive age attending Thika District Hospital, Kenya between July 2010 and February 2012. Women were given a multilingual flier outlining the study and were asked a series of questions to assess eligibility. To be included in the study, participants had to be between the ages of 18 - 49 years and willing to undergo a pelvic 
examination. Women who were pregnant or had vaginal bleeding were excluded from the study. Eligible women who expressed interest in participation were directed to a study interviewer who explained the study in greater detail, answered questions and obtained informed consent. Precoded questionnaires were used to collect socio-demographic and behavioral information about the participants. Women were screened for BV; Trichomonas vaginalis and vaginal candidiasis. The study was approved by the ethical review committee of Kenya medical research institute for protection of study subjects.

\section{Laboratory Methods}

Diagnostic testing was carried out in the Centre for microbiology research laboratory at Kenya medical research institute. Vaginal swabs from the posterior fornix were used for wet mount microscopy of Gram stain for diagnosis of BV using the Nugent scoring system [8]. Gram stains were interpreted independently by two study personnel and the inter-observer agreement was excellent. In addition, for treatment purposes, BV was diagnosed by vaginal specimens being cultured on Brucella and chocolate agar anaerobically at $37^{\circ} \mathrm{C}$ for a period of 18 - 72 hours. Colony morphotypes were evaluated on the basis of their size, colour and presence of heamolytic reactions on the culture media. They were further subjected to biochemical testing which involved use of enzymatic tests; catalase, coagulase and oxidase. Kanamycin and neomycin 1000 micrograms each were used as growth inhibitors against bacterial isolates. These antibiotics were used in biochemical testing as growth inhibitors whose zone of inhibition was considered in evaluating resistance or sensitivity. These were determined by standards established by national committee for control of laboratory standards guidelines. Monoclonal antibodies were used to help in further identification of the organisms. Quality control strains; American type culture colonies VI089 were used to confirm presence of Gardnerella vaginalis. Nugent score method was used to cluster BV into classical and non-classical [9].

\section{Data Analysis}

Correlational descriptive statistics were used to assess the characteristics of study participants. Univariate associations of baseline characteristics with BV were made using chi-square and with tests of significance being $(\mathrm{p}<0.05)$ and $95 \%$ confidence interval (CI). Behavioral or demographic characteristics from the study subjects were examined which included; age, education, marital status, contraceptive use and sexual risk behaviors. STATA software v 9.2 (Stata Corp LP, Texas USA) was used. The 95\% confidence intervals were calculated using an online tool available at confidence interval calculator for a completion rate [10].

\section{Results}

Of one hundred and ninety three specimens, 9.3\% were Mobiluncus isolates, 23.0\% Bacteriodes species and $67.7 \%$ Gardnerella vaginalis. The prevalence of BV was $43.1 \%$ with 92 (47.7\%) of study subjects aged between 21 - 30 years and the least 19 (9.8\%) aged 41 - 50 years. Of the study subjects, 99 (52.3\%) had secondary level of education, 7 (3.6\%) had no formal training and 33 (17.1 $\%)$ tertiary level education. Monthly income being an indicator of socioeconomic status, 104 (53.9\%) study subjects earned more than kshs 6000 per month while 89 (46.1\%) earned less than kshs 6000 per month.

Among the study participants, 40.9 (40.9\%) of the women were married and 91 (47.2\%) were single. The separated or divorced constituted 14 (7.3\%) while 9 (4.7\%) were widowed. Among the study subjects, 8 (4.1\%) of the women were nulliparous, 94 (48.7\%) had one child and 91 (47.1\%) had more than one child (Table 1).

Condom use was consistent with 43 (11.6\%) having classical BV while 40 (32.5\%) reported never using condoms. Among the study subjects, 11 (27.3\%) used intra uterine contraceptive device while 72 (20.8) did not use this method of family planning. Only 44 (13.6\%) reported more than one sexual partner in their life time from which 12 (30.5\%) maintained one consistent sexual partner had classical BV (Table 2).

The study subjects provided satisfactory vaginal swabs that were used to determine the prevalence of BV. The prevalence of BV was 43.1\%, (95\% CI 36.2 - 50.1) from which 77.7\%, (95\% CI 68.2 - 85.9) had non-classical BV with a score ranging from 7 - 8 while 22.4\%, (95\% CI 14.1 - 31.8) had classical BV with a score of 9 - 10 (Table 3).

\section{Discussions}

These findings confirm that women of child bearing age were affected by BV as in various settings and especially in sub-Saharan Africa [11]. The proportion of women with BV among the age group of 31 - 40 years had the highest prevalence of $32.1 \%$ which was in contrast to a study done on the same age group among American women [12]. The prevalence of BV on women from low socioeconomic stratum in USA was slightly lower than that in other reports from sub-Saharan Africa which ranged between 11\% - 30\%. [13] However, this may be attributable to low poverty index among women from sub-Saharan Africa. In addition, the magnitude of BV was slightly higher among women with no formal training 33.3\% this being in agreement with a study among STI clients within Nairobi area, were prevalence of 
Table 1. Socio-demographic characteristics of study subjects.

\begin{tabular}{|c|c|c|c|c|c|}
\hline \multirow[t]{2}{*}{ Characteristics } & \multicolumn{2}{|c|}{ Frequency } & \multirow[t]{2}{*}{$\mathrm{X}^{2}$} & \multirow[t]{2}{*}{ df } & \multirow[t]{2}{*}{$P$ value } \\
\hline & No & $\%$ & & & \\
\hline \multicolumn{6}{|l|}{ Age in years } \\
\hline $18-20$ & 29 & 15 & & & \\
\hline $21-30$ & 92 & 47.7 & 69.228 & 3 & $<0.05$ \\
\hline $31-40$ & 53 & 27.5 & & & \\
\hline $41-50$ & 19 & 9.8 & & & \\
\hline \multicolumn{6}{|l|}{ Education level } \\
\hline None & 7 & 3.6 & & & \\
\hline Primary & 54 & 27.9 & 94.15 & 3 & $<0.05$ \\
\hline Secondary & 99 & 52.3 & & & \\
\hline Tertiary & 33 & 17.1 & & & \\
\hline \multicolumn{6}{|l|}{ Monthly income } \\
\hline Less than kshs 6000 & 89 & 46.1 & 95.047 & 1 & $<0.05$ \\
\hline More than kshs 6000 & 104 & 53.9 & & & \\
\hline \multicolumn{6}{|l|}{ Marital status } \\
\hline Single & 91 & 47.2 & & & \\
\hline Married & 79 & 40.9 & 113.715 & 3 & $<0.05$ \\
\hline Widow & 9 & 4.7 & & & \\
\hline Separated divorced & 14 & 7.3 & & & \\
\hline \multicolumn{6}{|l|}{ Parity } \\
\hline None & 8 & 4.1 & & & \\
\hline 1 & 94 & 48.7 & 247.71 & 2 & $<0.05$ \\
\hline$>1$ & 91 & 47.1 & & & \\
\hline
\end{tabular}

No-number, \%-percentage.

35.0\% was reported. This shows that prevalence of BV varies widely among different areas and communities' globally $[14,15]$.

Among married women, BV prevalence of $32.4 \%$ was reported. This was far much less than prevalence reported among women in sub-Saharan Africa of $48.0 \%$. It was observed that, the prevalence of $\mathrm{BV}$ had a range between $50 \%$ and $60 \%$ in low resource settings. This might have added to the reasons for increased morbidity in such areas $[16,17]$.

In the study, Gardnerella vaginalis was the predominant organism that was isolated among majority $83.2 \%$ of the study subjects. However, a study in Uganda among women of reproductive age had found no association between Gardnerella vaginalis and BV. Furthermore, a cross over trial in Gambia STI clinics, found BV to be slightly more frequent among women who were com- mercial sex workers. Similarly, a study done in Thailand among commercial sex workers isolated Prevotella spp and Bacteriodes spp unlike in Thika District Hospital were only Bacteriodes spp were isolated. [18] The difference between these two populations might have being that women of reproductive age were a low risk population when compared to commercial sex workers. Mobiluncus spp was isolated among minority $22.4 \%$ of the study participants. The proportion of this organism was slightly low than that reported among pregnant women in sub Saharan Africa of 30.0\% [15,16].

Similarly, white vaginal discharge $(p=0.994)$ was the most common presenting symptom among the study subjects accounting for $19.1 \%$ of the cases. This concurs with a study done among sexually transmitted infection clients in Havana (Cuba) where study subjects had low level of knowledge on BV [19]. These were attributed to 
Table 2. Bivariate analysis of BV by reproductive profiles.

\begin{tabular}{|c|c|c|c|c|c|}
\hline \multirow[t]{2}{*}{ Characteristics } & \multirow[t]{2}{*}{ Frequency } & \multicolumn{2}{|c|}{ Classical BV } & \multirow[t]{2}{*}{$P$ value } & \multirow[t]{2}{*}{ Bivariete } \\
\hline & & No. & $\%$ & & \\
\hline \multicolumn{6}{|l|}{ Sexual partners } \\
\hline None & 0 & 0 & 0 & 0.050 & NS \\
\hline 1 & 39 & 12 & 30.5 & 0.990 & $\mathrm{O} .44(0.17-1.18)$ \\
\hline$>1$ & 44 & 6 & 13.6 & Referent & Referent \\
\hline \multicolumn{6}{|l|}{ Condom use } \\
\hline At last sexual act & 43 & 5 & 11.6 & 0.051 & $2.79(0.99-7.84)$ \\
\hline None & 40 & 13 & 32.5 & Referent & Referent \\
\hline \multicolumn{6}{|l|}{ IUCD use } \\
\hline Yes & 11 & 3 & 27.3 & 0.67 & $1.31(0.38-4.52)$ \\
\hline No & 72 & 15 & 20.8 & Referent & Referent \\
\hline \multicolumn{6}{|l|}{ Depo provera use } \\
\hline Yes & 27 & 8 & 29.6 & 0.17 & $1.96(0.74-5.23)$ \\
\hline No & 1 & 1 & 100 & Referent & Referent \\
\hline \multicolumn{6}{|l|}{ Vaginal discharge } \\
\hline None & 56 & 13 & 23.2 & Referent & \\
\hline White & 21 & 4 & 19.1 & 0.994 & NS \\
\hline Yellow & 3 & 1 & 33.3 & 0.994 & \\
\hline Others & 3 & 0 & 0 & 0.994 & \\
\hline \multicolumn{6}{|l|}{ Vaginal itchiness } \\
\hline Yes & 24 & 7 & 29.2 & 0.547 & $1.46(0.42-4.98)$ \\
\hline No & 39 & 7 & 17.9 & Referent & Referent \\
\hline
\end{tabular}

NS-not significant, PR-prevalence ratio, CI-confidence interval, No-Number, \%-percentage.

Table 3. Prevalence and categories of BV.

\begin{tabular}{|c|c|c|c|c|c|c|c|}
\hline \multicolumn{2}{|c|}{ Characteristics } & \multicolumn{2}{|c|}{ Frequency } & \multirow[t]{2}{*}{$95 \%$ CI } & \multirow[t]{2}{*}{$\mathrm{X}^{2}$} & \multirow[t]{2}{*}{ df } & \multirow[t]{2}{*}{$P$ value } \\
\hline & & No & $\%$ & & & & \\
\hline \multicolumn{8}{|c|}{ Nugent score category } \\
\hline Normal & $(0-3)$ & 92 & 47.7 & $40.7-54.7$ & & & \\
\hline Intermediate & $(4-6)$ & 18 & 9.3 & $5.9-14.3$ & 83.415 & 2 & $<0.05$ \\
\hline Overall BV & $(7-10)$ & 83 & 43.1 & $36.2-50.1$ & & & \\
\hline \multicolumn{8}{|c|}{ Categories of BV } \\
\hline Non-classical BV & $(7-8)$ & 65 & 77.7 & $68.2-85.9$ & & & \\
\hline Classical BV & $(9-10)$ & 18 & 22.4 & $14.1-31.8$ & & & \\
\hline
\end{tabular}

No-number, \%-percentage, CI-confidence interval.

genitourinary symptoms as related to sexually transmitted infections. Vaginal itchiness $(p=0.547)$ was the other reported symptom although it occurred among the minority $29.2 \%$ of study subjects. 
Elsewhere, studies have found BV to be associated with sexual activity in communities living in rural settings and among women at high risk of STIs. However, a prospective study of rural women in Gambia found no association between any sexual behavior and BV. A recent Meta-analysis found the epidemiological data to be consistent with BV having a sexual mode of transmission, but additional factors were likely to contribute to the risk [20-22].

Asymptomatic women were less likely to seek treatment for the morbidity and thus were more likely to acquire other STIs. In view of this, it is suggested that women attending various health care facilities including ante-natal clinics, gynecologic clinics, genitor-urinary clinics or family planning clinics should be screened and treated for $\mathrm{BV}$ to reduce the risk of acquiring STIs. In sub-Saharan Africa, the association between BV and male condom use is inconsistent; perhaps reflecting the heterogeneity of the formulations. In a prospective study of sex workers in Burkina Faso, condom use was not associated with BV. Also, among family planning attendees in Zimbabwe and Uganda, condom use was not associated with BV [23,24].

The study analyses being cross-sectional in nature, it was not possible to infer any causal association between risk factors and BV. In addition, risk factors were collected through face to face precoded questionnaires, thus there was a possibility of under-reporting and misclassification of risk behaviors. The survey involved collection of sensitive sexual behaviors, as well as information on women's sex partners, so there was a likelihood of measurement error that may have lead to residual confounding of the relationships.

\section{Conclusion}

Gardnerella vaginalis, Bacteriodes spp and Mobiluncus spp were associated with BV in this population. Sexual partner relationships and condom use were associated with $\mathrm{BV}$, this being attributed to low poverty index of the study subjects. The study participants were able to know their health status and the results produced enhanced intervention strategies for BV. The study generated an accessible data that may be used for further surveillance of BV.

\section{Acknowledgements}

This project was supported by ministry of medical services Kenya. The authors would like to thank Dr. David Mwangi, medical superintendent Thika District Hospital and Mr. Peter Mbugua, Laboratory technologist. Moreover, we appreciate Musa Otieno and David Mwangi for technical support, data analysis and write up and all the study participants who were involved in the study.

\section{REFERENCES}

[1] R. Amsel, A. Totten, D. Eschenbach and K. Holmes, "Non-Specific Vaginitis, Diagnostic Criteria Microbial and Epidemiologic Associations," American Journal of Medicine, Vol. 74, No. 1, 1983, pp. 14-22. doi:10.1016/0002-9343(83)91112-9

[2] J. Atashili, M. Ndumbe and J. Smith, "Bacterial Vaginosis and HIV Acquisition: A Meta-Analysis of Published Studies,” Journal of Infectious Diseases, Vol. 22, No. 12, 2008, pp. 1493-1501.

[3] E. Allworth and F. Peipert, "Prevalence of Bacterial Vaginosis: 2001-2004 National Health and Nutrition Examination Survey Data,” Obstetrics \& Gynecology, Vol. 109, No. 1, 2007, pp. 114-120. doi:10.1097/01.AOG.0000247627.84791.91

[4] M. Brotman, M. Klebanoff and R. Nansel, "Bacterial Vaginosis Assessed by Gram Stain and Diminished Colonization Resistance to Incident Gonococcal, Chlamydial, and Trichomonal Genital Infection,” Journal of Infectious Diseases, Vol. 202, No. 12, 2010, pp. 1907-1915. doi:10.1086/657320

[5] E. Bukusi, R. Cohen, S. Meier, G. Waiyaki, R. Nguti, N. Njeri and K. Holmes, "Bacterial Vaginosis: Risk Factors among Kenyan Women and Their Male Partners,” Sexually Transmitted Disease, Vol. 33, 2006, pp. 361-367.

[6] J. Christopher and V. Snehalata, "Syndromic Management of Vaginal Discharge among Women in a Reproductive Health Clinic in India," Sexually Transmitted Disease, Vol. 76, 2000, pp. 303-306.

[7] O. Fernández-Limia, C. Villar and R. Faure, "Prevalence of Trichomoniasis, Bacterial Vaginosis and Candidiasis in Women Attending Sexual Transmitted Infections and Gynecologic Clinic Using an Immunologic Latex Agglutination Test," American Journal of Obstetrics \& Gynecology, Vol. 166, 2007, pp. 938-934.

[8] N. Fredricks, L. Fiedler and M. Marrazzo, "Molecular Identification of Bacteria Associated with Bacterial Vaginosis," The New England Journal of Medicine, Vol. 353, No. 18, 2005, pp. 1899-1911. doi:10.1056/NEJMoa043802

[9] P. Nugent, A. Krohn and L. Hillier, "Reliability of Diagnosing Bacterial Vaginosis is Improved by a Standardized Method of Gram Stain Interpretation," Journal of Clinical Microbiology, Vol. 29, No. 2, 1991, pp. 297-301.

[10] http://www.measuringusability.com/wald.htm

[11] K. Fonck, N. Kidula, N. Temmerman and W. Jaoko, B. Estimable and P. Claeys, "Sexually Transmitted Infections and Pelvic Inflammatory Disease,” American Journal of Epidemiology, Vol. 162, 2000, pp. 585-590.

[12] H. Koumans, M. Sternberg and C. Bruce, "The Prevalence of Bacterial Vaginosis in the United States, 20012004; Associations with Symptoms, Sexual Behaviors, and Reproductive Health,” Sexually Transmitted Disease, Vol. 34, 2007, pp. 864-869.

[13] E. H. Koumans, L. E. Markowitz, V. Hogan and CDC BV Working Group, “Indications for Therapy and Treatment Recommendations for Bacterial Vaginosis in Non Pregnant and Pregnant Women: A Synthesis of Data,” Clini- 
cal Infectious Diseases, Vol. 35, No. 2, 2002, pp. 152172. doi: $10.1086 / 342103$

[14] J. Bornstein and H. Abramovici, "The Classis Approach to Diagnosis of Vulvo-Vaginitis: A Critical Analysis," Infect Disease in Obstetrics and Gynecology, Vol. 164, No. 2, 2001, pp. 105-111. doi:10.1155/S1064744901000187

[15] L. Gardner and D. Dukes, "Haemophilus vaginalis vaginitis: A Newly Defined Specific Infection Previously Classified Non-Specific Vaginitis," American Journal of Obstetrics and Gynecology, Vol. 69, 1955, pp. 962-976.

[16] F. Lamont, J. Sobel and A. Akins, "The Vaginal Microbiome: New Information about Genital Tract Flora Using Molecular Based Techniques,” BJOG, Vol. 118, No. 5, 2011, pp. 533-549. doi:10.1111/j.1471-0528.2010.02840.x

[17] S. Löfmark, C. Edlund and E. Nord, "Metronidazole Is Still the Drug of Choice for Treatment of Anaerobic Infections," Clinical Infectious Diseases, Vol. 50, No. 1, 2010, pp. S16-S23. doi:10.1086/647939

[18] P. Menard, F. Fenollar, M. Henry, F. Bretelle and D. Raoult, "Molecular Quantification of Gardnerella vaginalis and Atopobium vaginae Loads to Predict Bacterial Vaginosis," Clinical Infectious Diseases, Vol. 47, No. 1, 2008, pp. 33-43. doi:10.1086/588661

[19] H. Mikamo, K. Kawazoe, K. Izumi, K. Watanabe, K.
Ueno and T. Tamaya, "Comparative Study on Vaginal or Oral Treatment of Bacterial Vaginosis,” Chemotherapy, Vol. 43, No. 1, 1997, pp. 60-68. doi:10.1159/000239537

[20] J. Sobel, F. Peipert and J. McGregor, "Efficacy of Clindamycin Vaginal Ovule (3-Day Treatment) vs Clindamycin Vaginal Cream (7-Day Treatment) in Bacterial Vaginosis,” Infectious Diseases in Obstetrics and Gynecology, Vol. 9, No. 1, 2001, pp. 9-15. doi:10.1155/S1064744901000035

[21] E. Calzolari, R. Masciangelo and V. Milite, "Bacterial Vaginosis and Contraceptive Methods," American Journal of Obstetrics and Gynecology, Vol. 70, No. 3, 2000, pp 341-346.

[22] R. Cohen, P. Garcia and K. Nelson, "Bacterial Vaginosis and HIV Seroprevalence among Female Commercial Sex Workers in Chiang Mai, Thailand," American Journal of Obstetrics and Gynecology, Vol. 9, 1992, pp. 1093-1097.

[23] P. Hay, N. Ugwumadu and T. Manyonda, "Oral Clindamycin Prevents Spontaneous Preterm Birth and Mid Trimester Miscarriage in Pregnant Women with Bacterial Vaginosis," The International Journal of STD \& AIDS, Vol. 12, No. 2, 2001, pp. 70-71.

[24] C. Miller, H. Swygard and M. Hobbs, "The Prevalence of Trichomoniasis in Young Adults in the United States," Sexually Transmitted Disease, Vol. 32, 2005, pp. 593598. 